\title{
Psychopathological Symptoms as a Function of Trauma, Dreams, and Inhibitions
}

\author{
Calvin Kai-Ching Yu \\ Hong Kong Shue Yan University
}

This study investigates the cumulative effects of lifetime traumatization on dream activities and the extent to which potentially traumatic events, dream variables, and inhibitory functions can predict the severities of psychopathological symptoms. The sample consisted of 564 young adults, whose dream experiences, trauma history, ego functions, and symptom manifestations were assessed using the Dream Intensity Scale, Dream Motif Scale, Traumatic Experiences Checklist, and Ko's Mental Health Questionnaires, respectively. The 2 dream scales profile an individual's phenomenological experience of dream activities by retrospectively quantifying some typical dream themes - such as being pursued and encountering a person whom is desiredand variables indicative of subjective dream intensity, for example, nightmare frequency, lucid dreaming frequency, and confusion between real and dreamed events. The overall results suggest that psychopathological symptoms can be predicted positively by emotional trauma, accumulated traumatic experiences, thematic dream content, and sexual suppression (resistance against activity, material, or conversation relating to sex) and negatively by repressive defensiveness (denial of negative attributes) and counterdependence (active resistance against relying on other people) with impressive effect sizes.

Keywords: dream motifs, psychopathology, repression, sexual suppression, trauma

Supplemental materials: http://dx.doi.org/10.1037/a0038438.supp

The episode of recurrent frightening dreams is regarded as a diagnostic marker for acute stress disorder, posttraumatic stress disorder, and nightmare disorder in both the Diagnostic and Statistical Manual of Mental Disorders, fourth edition, text revision (DSM-IV-TR; American Psychiatric Association, 2000) and International Statistical Classification of Diseases and Related Health Problems, tenth edition, revised (ICD-10; World Health Organization, 2007). Nevertheless, distressing dreams are not unique to these three disorders; many other mental disorders emerge concurrently with intensified nocturnal conscious activities. Mounting evidence indicates that dream experiences - especially those that are unpleasantare positively associated with various psychological symptoms, ranging from

Correspondence concerning this article should be addressed to Calvin Kai-Ching Yu, Department of Counselling and Psychology, Hong Kong Shue Yan University, 10 Wai Tsui Crescent, Braemar Hill Road, North Point, Hong Kong. E-mail: calvinkcyu@ymail.com 
anxiety (e.g., Blagrove \& Fisher, 2009; Gregory \& Eley, 2005; Kroth, Jensen, \& Haraldsson, 1997; Yu, 2010a, 2010b, 2012a, 2012b, 2013a, 2013b, 2013c), through to depressive mood (e.g., Beauchemin \& Hays, 1996; Blagrove \& Fisher, 2009; Bjorvatn, Grønli, \& Pallesen, 2010; Mancuso et al., 2008; Nejad, Sanatinia, \& Yousofi, 2004; Schredl \& Engelhardt, 2001; Yu, 2010a, 2010b, 2012a, 2012b, 2013a, 2013b, 2013c), psychosomatic dissociation (e.g., Agargun et al., 2003; Giesbrecht \& Merckelbach, 2006a; Giesbrecht \& Merckelbach, 2006b; Suszek \& Kopera, 2005; Yu, 2010b, 2011c), borderline personality (e.g., Schredl et al., 2012; Semiz et al., 2008; Yu, 2013a), and psychoticism (e.g., Miró \& Martínez, 2005; Stompe et al., 2003). There is also evidence that dream profiling can be instrumental in discerning individuals with a strong inclination to borderline personality ( $\mathrm{Yu}, 2013 \mathrm{a})$, conversion disorder (Yu, 2010b, 2011c), pathological dissociation (Yu, 2010b, 2011c), schizotypal personality ( $\mathrm{Yu}, 2013 \mathrm{a}$ ), or obsessive-compulsion (Yu, 2013a). Obsessive-compulsive distress, for instance, is indicated by dream narratives featuring superego-ego ideal functioning (Yu, 2013a), whereas conversion disturbance is better signified by symbolism and persecutory themes in dreams (Yu, 2011c).

As with dreaming, although the diagnostic criterion of trauma exposure applies only to acute stress disorder and posttraumatic stress disorder in the $D S M-I V-T R$ and ICD-10, traumatic experiences have long been known to play a part in the development of symptoms pertaining to other forms of psychopathology, including, but not limited to, borderline personality (e.g., Gaher et al., 2013; Kaehler, \& Freyd, 2012; van Dijke et al., 2013), somatization (e.g., Güleç et al., 2013; Kuwert et al., 2012; Waldinger et al., 2006), pathological dissociation (e.g., Dalenberg \& Carlson, 2012; Ross et al., 2008; Ross \& Ness, 2010; Xiao et al., 2006), and schizophrenia-spectrum disorders (e.g., Read \& Ross, 2003; Read et al., 2005; van Winkel et al., 2013). Consistent with this phenomenon, a national survey by Pietrzak et al. (2011a, 2001b, 2012) provided compelling evidence that posttraumatic stress disorder has high comorbidity rates with anxiety disorders, mood disorders, borderline personality, narcissistic personality, and schizotypal personality. In a bid to solve the comorbidity issue in diagnosis, Ross (2000) proposed a model in which chronic trauma is posited as the common contributing factor that threads many psychiatric disorders together.

There is indeed a triangular relationship between dreaming, psychopathology, and trauma in that traumatic experiences can increase dream salience and dream recall frequency (e.g., Cosman, 2013; Hartmann et al., 2001; Helminen \& Punamäki, 2008; Najam et al., 2006; Punamäki, 1997; Valli et al., 2006) and can be directly or metaphorically carried over into the narrative content of dreams (e.g., Cosman, 2013; Gackenbach, Ellerman, \& Hall, 2011; Kamphuis et al., 2008; Phelps et al., 2011; Punamäki, 1998; Valli et al., 2006). Survivors of life-threatening events, especially war victims, have been a major target population studied by dream researchers (e.g., Cosman, 2013; Gackenbach et al., 2011; Helminen \& Punamäki, 2008; Phelps et al., 2011; Valli et al., 2006). A majority of people, however, have probably encountered some ordeals at one point or another in life and have experienced certain symptoms that may not necessarily warrant a clinical diagnosis. Terminal illness and death - that is, the most severe forms of trauma, according to Pietrzak et al. (2011a, 2012) - are ipso facto unavoidable. Likewise, traumatization and its concomitant impacts on dreams can take effect through vicarious conditioning (Davidson et al., 2005; Propper et al., 2007). 
[T]he development of characteristic symptoms following exposure to an extreme traumatic stressor involving direct personal experience of an event that involves actual or threatened death or serious injury, or other threat to one's physical integrity; or witnessing an event that involves death, injury, or a threat to the physical integrity of another person; or learning about unexpected or violent death, serious harm, or threat of death or injury experienced by a family member or other close associate. (American Psychiatric Association, 2000, p. 463)

The examples of trauma illustrated in the $D S M-I V-T R$ are confined to the physical type. Although sexual assault is included in the DSM-5 (American Psychiatric Association, 2013), the scope of trauma can be even more broadly defined to encompass all those psychological sufferings, such as parentification, humiliation, and emotional neglect. In a similar vein, trauma can be prolonged, repeated, and exacerbated rather than a one-off episode, and reactions or resilience to trauma and the amount of support received from others most likely vary across individuals. Accordingly, although most people may have gone through traumatizing events of various types, with various levels of brutality, not every individual who experiences a painful event would become psychologically traumatized. Indeed, some questionnaires, such as Traumatic Experiences Checklist (Nijenhuis, Van der Hart, \& Kruger, 2002), are designed to distinguish between the exposure to potentially traumatizing events and the degree of the actual psychological traumatization that an individual subjectively experience.

There have thus far been very few, if any, studies attempting to consider the cumulative effects of lifetime traumatization on dream activities and to predict pathological inclinations with both the subjective intensities of traumatic and dream experiences. This study was therefore geared toward investigating the extent to which traumatic can predict the severities of psychopathological symptoms, taking dream experiences - that is, the significant correlates of both pathological tendencies and traumatic experiences - into consideration. Inhibition can be broadly defined as any defense or restriction exercised by the ego to accommodate intrapsychic conflicts that could possibly lead to neurosis. Repressive defense, for instance, protects the ego from the awareness of disagreeable attributes and memories, including dream material derived from wicked ideas and motives. Inhibition as a form of ego defense or restriction is pivotal in both symptom and dream formation (see Yu, 2011b, 2011c, 2013b, 2013c, for details). Moreover, from the psychoanalytic perspective, trauma is a devastating event that disrupts the normal ego functions and coping mechanisms. Therefore, measures for assessing ego strength and inhibitions were also included in the prediction models.

\section{METHOD}

\section{Participants}

The present sample contained 564 young adults, 176 (31.2\%) males and 388 $(68.8 \%)$ females. The mean age was $19.28(S D=1.20$, range $=17-25)$. Most participants, who were recruited on university admission days, completed upper-secondary school in Hong Kong. Participation was voluntary and without payment. 


\section{Instruments}

The Dream Intensity Scale (DIS), Dream Motif Scale (DMS), Traumatic Experiences Checklist (TEC), and Ko's Mental Health Questionnaire (KMHQ) were used to assess participants' subjective dream intensity, tendencies to dream particular sets of themes, severity of traumatic experiences, ego functions, and psychopathological symptoms, respectively. All these questionnaires were administered in Chinese.

\section{DIS}

The DIS (Yu, 2012b) comprises 23 items measuring four primary factors for dream intensity: Dream Quantity, Dream Vividness, Diffusion, and Altered Dream Episodes. The development and psychometric properties of the DIS are available in previous reports (Yu, 2008b, 2009b, 2010a, 2012b).

\section{$D M S$}

$\mathrm{Yu}$ (2012a) designed the DMS to evaluate the intrinsic predispositions that modulate the fabrication of dream narratives. It consists of 100 dream themes, various combinations of which can form 14 scales, each measuring a dream predisposition. The Persecution scale, for instance, comprises some delusional themes that are often observed in paranoid schizophrenia, such as being chased or pursued, some people plotting against you, and encountering a devil in some form. The development and psychometric properties of the DMS are available in previous reports (Yu, 2008a, 2009a, 2009c, 2010c, 2012a).

\section{TEC}

The TEC (Nijenhuis, Van der Hart, \& Kruger, 2002) evaluates 29 types and three major categories of potentially traumatic events that may happen to both children and adults: emotional trauma, bodily threat, and sexual trauma (see Table 1). A severity score can be calculated for each type and each category based on four indicators: (a) presence of the event, (b) age of onset, (c) duration of trauma, and (d) the degree of impact that the respondent subjectively feels. In addition to these four indicators, the TEC also inquires about the level of support received for each traumatic event. In this study, the total number of trauma types and the total trauma severity score were calculated using all 29 item scores.

\section{KMHQ}

The KMHQ (Ko, 1998) is a 300-item questionnaire. Participants rated the degree to which each statement could apply to them on a 6-point scale, $1=$ not at all true to $6=$ completely true. The severities of pathological symptoms were 
Table 1. Prevalence of Traumatic Experiences $(n=564)$

\begin{tabular}{|c|c|c|}
\hline TEC categories and types & Frequency & Percentage \\
\hline Emotional trauma & 197 & 34.9 \\
\hline Emotional neglect & 115 & 20.4 \\
\hline 14 Emotional neglect by member of family of origin & 79 & 14.0 \\
\hline 15 Emotional neglect by other family member & 20 & 3.5 \\
\hline 16 Emotional neglect by nonfamily member & 56 & 9.9 \\
\hline Emotional abuse & 136 & 24.1 \\
\hline 17 Emotional abuse by member of family of origin & 101 & 17.9 \\
\hline 18 Emotional abuse by other family member & 23 & 4.1 \\
\hline 19 Emotional abuse by nonfamily member & 53 & 9.4 \\
\hline Bodily threat & 232 & 41.1 \\
\hline Physical abuse & 117 & 20.7 \\
\hline 20 Physical abuse by member of family of origin & 112 & 19.9 \\
\hline 21 Physical abuse by other family member & 4 & 0.7 \\
\hline 22 Physical abuse by nonfamily member & 8 & 1.4 \\
\hline \multicolumn{3}{|l|}{ Other bodily threat items } \\
\hline 9 Deliberate threat to life from another person, e.g., during crime & 14 & 2.5 \\
\hline 10 Intense pain from illness, medical treatment, etc. & 150 & 26.6 \\
\hline 23 Bizarre punishment & 14 & 2.5 \\
\hline Sexual trauma & 50 & 8.9 \\
\hline Sexual harassment & 30 & 5.3 \\
\hline 24 Sexual harassment by member of family of origin & 3 & 0.5 \\
\hline 25 Sexual harassment by other family member & 2 & 0.4 \\
\hline 26 Sexual harassment by nonfamily member & 27 & 4.8 \\
\hline Sexual abuse & 24 & 4.3 \\
\hline 27 Sexual abuse by member of family of origin & 0 & 0.0 \\
\hline 28 Sexual abuse by other family member & 5 & 0.9 \\
\hline 29 Sexual abuse by nonfamily member & 19 & 3.4 \\
\hline \multicolumn{3}{|l|}{ Other trauma types } \\
\hline 1 Parentification & 95 & 16.8 \\
\hline 2 Family problems & 105 & 18.6 \\
\hline 3 Loss of a family member in childhood & 41 & 7.3 \\
\hline 4 Loss of own child or partner in adulthood & 13 & 2.3 \\
\hline 5 Severe bodily injury & 14 & 2.5 \\
\hline 6 Threat to life from illness, surgery, accident, torture & 50 & 8.9 \\
\hline 7 Divorced parents & 74 & 13.1 \\
\hline 8 Own divorce & 0 & 0.0 \\
\hline 11 War experience & 4 & 0.7 \\
\hline 12 Second generation war victim & 23 & 4.1 \\
\hline 13 Witnessing others undergo trauma & 186 & 33.0 \\
\hline
\end{tabular}

assessed by 18 KMHQ scales (see Table 2). The ego functions were measured by the KMHQ ego strength, impression management (repressive defensiveness), counterdependence, and sexual suppression scales. High scorers on the ego strength scale are characterized by their self-confidence, belief in changing one's own personality, and ability to solve daily problems and make flexible adjustments. The impression management scale consists of 12 statements similar to those of the Marlowe-Crowne Social Desirability Scale (Crowne \& Marlowe, 1960), which is considered a valid measure of repressive defensiveness (see Yu, 2011b, 2013b, for details). The counterdependence scale measures the level of active resistance against relying on other people. Items of the sexual suppression scale are concerned with sexual attitudes and behaviors, such as lack of sexual desire, resistance against the opposite sex, and refraining from talking about sex, watching pornographic movies, or reading books involving sex. 


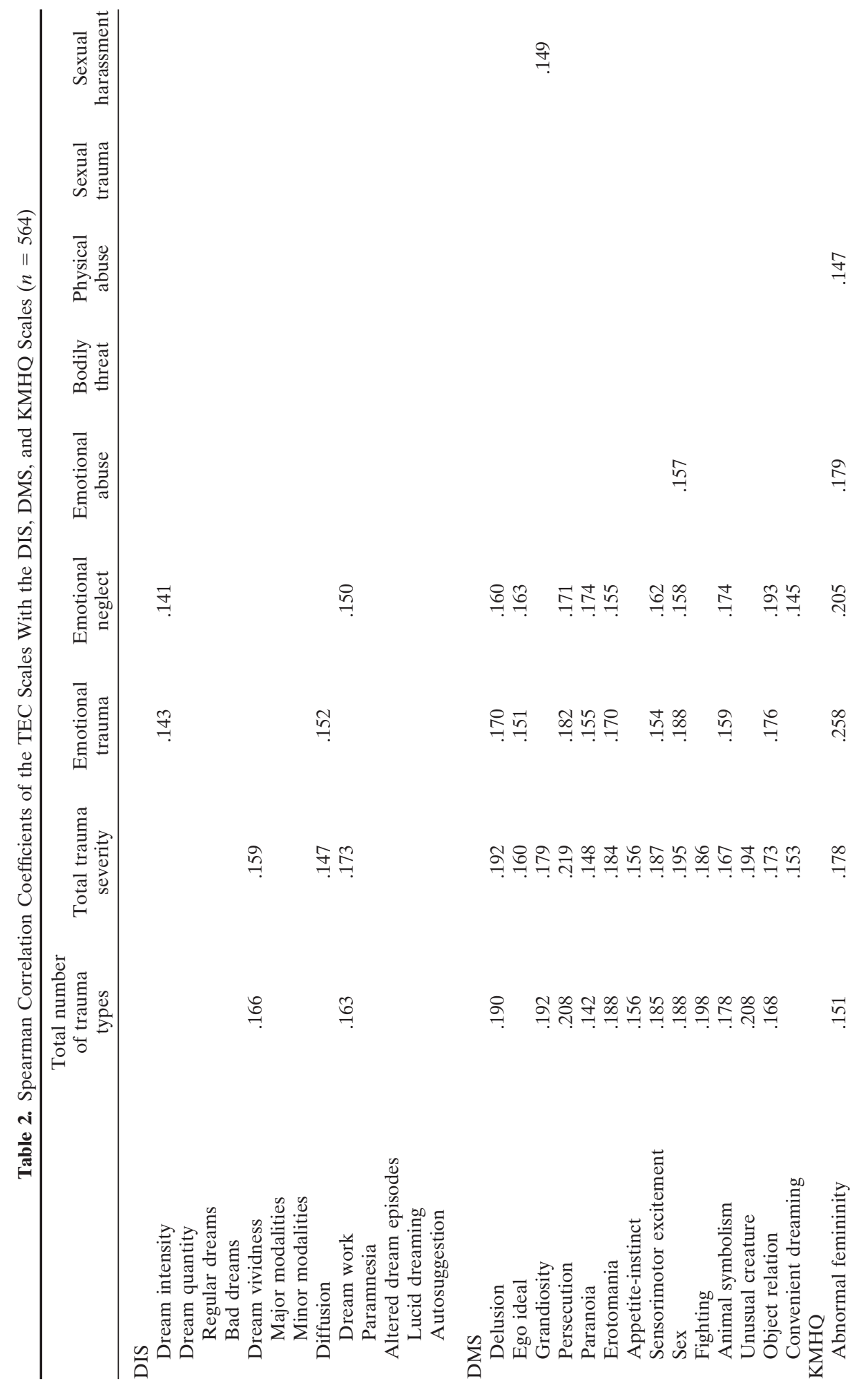




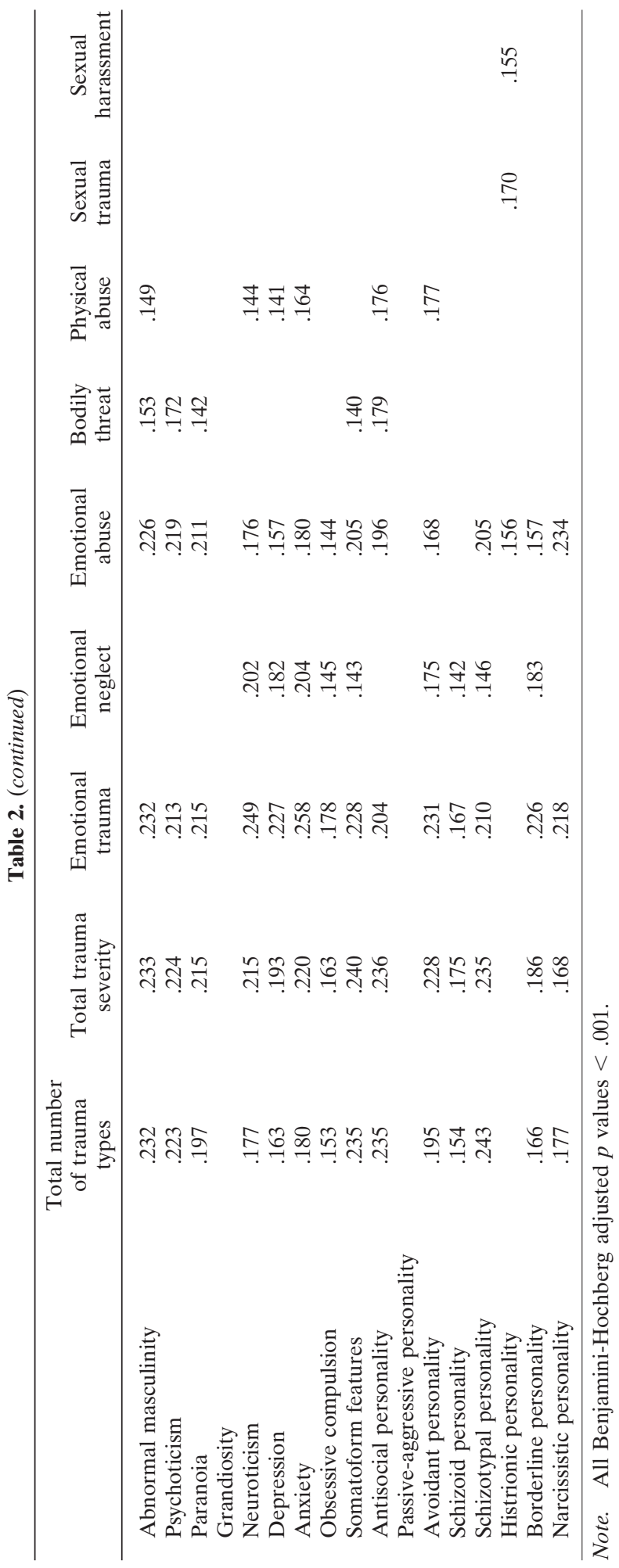




\section{Statistical Strategies}

The significance level was set at .001 for single hypothesis testing. The significance threshold was further adjusted with reference to the BenjaminiHochberg procedure to control false discovery rate in multiple hypothesis testing (e.g., four upper and eight lower factor scores of the DIS). Pearson $\chi^{2}$ and Mann-Whitney $U$ tests were used to test the differences in the DIS, DMS, and KMHQ scales between sexes and between participants having experienced potentially traumatizing events and participants without such experiences. The correlations of the number of trauma types and the eight TEC severity scores with 13 DIS, 14 DMS, and $18 \mathrm{KMHQ}$ scores were examined before regression analyses (see Table 2). The strongest correlate of each KMHQ pathological scale and the remaining significant correlates, the items of which were not encompassed by the strongest correlate, were entered into the linear stepwise regression analysis (see Online Appendix 3). This prevented psychometric overlapping between predictors.

\section{RESULTS}

A majority of the sample $(81.6 \%)$ had experienced at least one of the 29 trauma types listed in the TEC. The average number of trauma types reported by participants was $2.30(S D=2.085$, Range $=0-11)$. Bodily threats were more common than emotional and sexual traumas (see Table 1). Intense pain caused by illness or medical treatment was the most prevalent type of trauma. In addition, a third of the sample had observed other people undergoing a traumatic event. A significantly larger proportion of women $(11.9 \%)$ than men $(2.3 \%)$ had experienced sexual trauma, Pearson $\chi^{2}=13.9, p<.001, \phi=.157$. On the other hand, men $(37.5 \%)$ were significantly more likely than women $(21.6 \%)$ to experience intense pain, Pearson $\chi^{2}=15.6, p<.001, \phi=-.166$. The mean scores for all TEC severity scales are provided in Online Appendix 1 of the online supplementary materials.

Men scored significantly higher on the DMS fighting scale $(z=4.950, p<.001$, Cohen's $d=0.460)$ and the KMHQ psychoticism $(z=5.080, p<.001$, Cohen's $d=$ $0.497)$, schizoid ( $z=5.388, p<.001$, Cohen's $d=0.517)$, and antisocial personality scales $(z=4.742, p<.001$, Cohen's $d=0.491)$ than did women. A sex difference was also found in seven other KMHQ scales (see Online Appendix 2 of the online supplementary materials). Participants who had experienced emotional trauma scored significantly higher on seven dream scales and most KMHQ scales, the effect sizes for the KMHQ abnormal femininity $(z=5.785, p<.001$, Cohen's $d=0.542)$ and anxiety $(z=5.648, p<.001$, Cohen's $d=0.525)$ scales being the largest (see Online Appendix 2 of the online supplementary materials). By contrast, only the psychoticism $(z=3.388, p<.001$, Cohen's $d=0.304)$ and antisocial personality scales $(z=3.510, p<.001$, Cohen's $d=0.311)$ showed a significant difference between participants with bodily threat and participants without bodily threat across all dream and KHMQ scales. Participants who had been sexually harassed exhibited a significantly higher score on the DMS grandiosity $(z=3.518, p<.001$, Cohen's $d=0.621)$ and KHMQ histrionic personality $(z=3.678, p<.001$, Cohen's $d=0.789$ ) scales than did participants without the similar trauma. 
Table 2 shows the significant correlations of the TEC scales with dream and KMHQ scales. The total number of trauma types, the total trauma severity score, and the emotional trauma severity score were positively correlated with almost all DMS and KMHQ pathological scales. Overall, the dream scale scores were more sensitive to the variation in scores on the emotional neglect scale than to that on the emotional abuse scale. The TEC bodily threat and physical abuse scores were significantly correlated with some KMHQ pathological traits, such as abnormal masculinity and antisocial personality, but not with any dream scales. The KMHQ ego strength showed a positive association with the total level of support received during or after traumas, $r_{\mathrm{s}}=0.155, p<.001$. The TEC sexual abuse score did not significantly vary with any dream or KMHQ scales.

The regression models for predicting 16 categories of psychopathological symptoms are summarized in Online Appendix 3. Because KMHQ grandiosity and passive-aggressive personality were not significant correlated with any TEC scales, no regression analysis was conducted for these two pathological traits. All 16 regression analyses factored KMHQ inhibition and DMS scales into the solutions. The effect sizes for the variance explained by the obsessive-compulsion model and the schizotypal personality model were medium (Cohen's $f^{2}>0.15$ ). The Cohen's $f^{2}$ value for all remaining regression models far exceeded the 0.35 level, indicating a very large effect size.

The model for abnormal femininity was formed by only four factors - the KHMQ counterdependence, KMHQ sexual suppression, TEC emotional trauma, and DMS persecution - but could account for $63.4 \%$ of variance. These four factors, together with the KHMQ repressive defensiveness and TEC total trauma severity, constituted some common predictors included in the 16 regression models. Repressive defensiveness and counterdependence functioned as negative predictors in the models, sexual suppression being directly proportional to almost all pathological tendencies, except antisocial, histrionic, and narcissistic personalities. Notwithstanding their positive association with sexual suppression, somatoform features, depression, and psychoticism were significantly predicted by higher scores on the DMS sex scale. The ego strength and counterdependence scores were correlated positively with the repressive defensiveness score $\left(r_{\mathrm{s}}=0.435, p<.001\right.$; $\left.r_{\mathrm{s}}=346, p<.001\right)$, and inversely with the sexual suppression score $\left(r_{\mathrm{s}}=-0.307\right.$, $\left.p<.001, r_{\mathrm{s}}=-0.244, p<.001\right)$.

\section{DISCUSSION}

A common criticism about the application of retrospective scales in quantifying dream variables is that the recall of dream activities can be distorted in ways that are determined by psychological factors. It can be argued, furthermore, that the relationship between dream experiences and pathological tendencies is mediated by personality traits. A prominent example of these probable mediators is neuroticism, which has been repeatedly demonstrated to have associations with both dream variables and pathological tendencies.

Nonetheless, three caveats should be highlighted. First, some aspects and episodes of nocturnal mentation-such as the incidence of dreaming specific categories of themes and exerting control over dream content-are not easily 
captured by dream samples collected by a nightly log within a fixed period of time. Accordingly, the extent to which a few diary dream narratives can represent a person's characteristics of nocturnal mentation is questionable. Perhaps, questionnaires - the widely accepted approach to personality assessment-more effectively serve the purpose of profiling dream experiences as a trait of consciousness. Second, subjective intensities of dream experiences contribute additional variance to the models for identifying psychopathological tendencies even with critical personality factors that are known to be correlated with both dream variables and psychopathological tendencies being taken into account (Yu, 2010b, 2011c, 2013a). In other words, those factors such as neuroticism and defense mechanisms act as moderators rather than mediators in the relationship between dream experiences and psychopathological tendencies.

Last, but not least, whether an objective event would be reported as sexual harassment, emotional abuse, or other traumas, which is indeed similarly influenced by personality, pathology, demographics, and "response bias," such as losing memory of abuse and motivations for malingering, is just as subjective as the retrospective measures of dream activities. For instance, men and victims who have been more severely maltreated are more likely to report subjective forgetting of child sexual abuse (Ghetti et al., 2006). Likewise, it has been demonstrated that the concordance between parents and affected children on reports of exposure to trauma, impact of trauma, and posttraumatic stress symptoms is low (Stover, Hahn, Im, \& Berkowitz, 2010).

More than $80 \%$ of participants in the current sample experienced at least one type of probable traumatization. The total number of trauma types and the global trauma severity score were found to be positively correlated with almost all DMS and KMHQ pathological scales, suggesting that repeated or chronic exposure to potentially traumatic events can have cumulative effects on dream and mental experiences. Although bodily threats are more common than emotional and sexual traumas, both dream and pathological variables are more sensitive to emotional traumatization than to physical traumatization. It seems that the mechanisms of dreaming are predisposed to processing affective rather than corporeal memories; instead of physical threats per se, perhaps it is their concomitant emotive turmoil that alters dream experiences and mental conditions. This coincides with the theory that affect regulation is the inherent function of dreaming (e.g., Cartwright, Baehr, Kirkby, Pandi-Perumal, \& Kabat, 2003; Cartwright, Luten, Young, Mercer, \& Bears, 1998; Kramer, 1993; Kramer \& Brik, 2002; Yu, 2001, 2003, 2007). Given the small coefficient values, however, the significant correlations between the TEC and dream scales should be interpreted with caution although this result is not unexpected in that traumatization is merely one of the many factors that modulate the phenomenological experience of dreaming.

Because traumatization has significant impacts on both pathological tendencies and dream characteristics, it can be argued that any change in dream experiences is an epiphenomenon that occurs alongside but independently of the primary symptoms. For that reason, it is of theoretical importance to test whether dream parameters still hold predictive values when a person's previous history of traumatic experiences being factored into the regression models for predicting pathological tendencies. The study presented here demonstrates that dream variables, especially the thematic content of dreams, serve as significant indicators 
of all categories of pathological symptoms even after controlling the history of traumatization, the level of support received, and some important ego factors. The effect sizes were impressive in that the regression models comprising trauma, dream, and ego function scales could explain up to $63 \%$ of variance in scores on a pathological scale. There seem to be some common predictors shared by different pathological inclinations - that is, the severity of purely emotional trauma, the cumulative severity of all previous potentially traumatic experiences, persecutory and sexual dream themes, repressive defensiveness, counterdependence, and sexual suppression.

Antisocial, histrionic, and narcissistic personalities are distinguished by their unrestrained sexual desire in both dream and waking life. With the exception of these three pathological traits, all other categories of symptom manifestations were found to vary positively with sexual suppression and negatively with repressive defensiveness and counterdependence. Accordingly, the inhibitory function can undergo a splitting process whereby the ego gives up safeguarding its integrity and autonomy on the one hand, while on the other hand, denies its sexual impulses, which paradoxically rebound during dreaming. Erotic and persecutory dreams, however, are not unique to people suffering from salient symptoms. Many items that make up the DMS scales are indeed typical themes dreamed by ordinary people (Yu, 2008a, 2009a, 2009c, 2010c, 2011a, 2012a). Although all human beings share the same basic needs, the extent to which these needs can be gratified varies across people and time. Unusually high occurrence of certain themes in dreams may underscore the significance of what the sick are deprived of.

\section{CONCLUSION}

Perhaps, recurrent trauma puts a person on a downward spiral toward psychopathology. The more traumatizing events people subjectively experience, the less support they perceive, and the more they are likely to experience symptoms. As a result, the ego is debilitated and is rendered more susceptible to next potential trauma. At night, this emotional turbulence continues to ripple through the metaphoric milieu of dreaming.

\section{REFERENCES}

Agargun, M. Y., Kara, H., Özer, Ö. A., Selvi, Y., Kiran, U., \& Kiran, S. (2003). Nightmares and dissociative experiences: The key role of childhood traumatic events. Psychiatry and Clinical Neurosciences, 57, 139-145. http://dx.doi.org/10.1046/j.1440-1819.2003.01093.x

American Psychiatric Association. (2000). Diagnostic and statistical manual of mental disorders (4th ed., text revision). Washington, DC: Author.

American Psychiatric Association. (2013). Diagnostic and statistical manual of mental disorders (5th ed.). Arlington, VA: Author.

Beauchemin, K. M., \& Hays, P. (1996). Dreaming away depression: The role of REM sleep and dreaming in affective disorders. Journal of Affective Disorders, 41, 125-133. http://dx.doi.org/ 10.1016/S0165-0327(96)00080-8

Bjorvatn, B., Grønli, J., \& Pallesen, S. (2010). Prevalence of different parasomnias in the general population. Sleep Medicine, 11, 1031-1034. http://dx.doi.org/10.1016/j.sleep.2010.07.011

Blagrove, M., \& Fisher, S. (2009). Trait-state interactions in the etiology of nightmares. Dreaming, 19, 65-74. http://dx.doi.org/10.1037/a0016294 
Cartwright, R., Baehr, E., Kirkby, J., Pandi-Perumal, S. R., \& Kabat, J. (2003). REM sleep reduction, mood regulation and remission in untreated depression. Psychiatry Research, 121, 159-167. http://dx.doi.org/10.1016/S0165-1781(03)00236-1

Cartwright, R., Luten, A., Young, M., Mercer, P., \& Bears, M. (1998). Role of REM sleep and dream affect in overnight mood regulation: A study of normal volunteers. Psychiatry Research, 81, 1-8. http://dx.doi.org/10.1016/S0165-1781(98)00089-4

Cosman, I. (2013). Remembering the Holocaust: Dreams during and after a long traumatic experience. Philobiblon: Transylvanian Journal of Multidisciplinary Research in Humanities, 18, 116-126.

Crowne, D. P., \& Marlowe, D. (1960). A new scale of social desirability independent of psychopathology. Journal of Consulting Psychology, 24, 349-354. http://dx.doi.org/10.1037/h0047358

Dalenberg, C., \& Carlson, E. B. (2012). Dissociation in posttraumatic stress disorder part II: How theoretical models fit the empirical evidence and recommendations for modifying the diagnostic criteria for PTSD. Psychological Trauma: Theory, Research, Practice, and Policy, 4, 551-559. http://dx.doi.org/10.1037/a0027900

Davidson, J., Hart, K., \& Haines, J. (2005). Contextualising imagery in dreams following a September 11 video from television news. Australian Psychologist, 40, 202-206. http://dx.doi.org/ 10.1080/00050060500243442

Gackenbach, J., Ellerman, E., \& Hall, C. (2011). Video game play as nightmare protection: A preliminary inquiry with military gamers. Dreaming, 21, 221-245. http://dx.doi.org/10.1037/a0024972

Gaher, R., Hofman, N., Simons, J., \& Hunsaker, R. (2013). Emotion regulation deficits as mediators between trauma exposure and borderline symptoms. Cognitive Therapy and Research, 37, 466-475. http://dx.doi.org/10.1007/s10608-012-9515-y

Ghetti, S., Edelstein, R. S., Goodman, G. S., Cordòn, I. M., Quas, J. A., Alexander, K. W., . . Jones, D. P. H. (2006). What can subjective forgetting tell us about memory for childhood trauma? Memory \& Cognition, 34, 1011-1025. http://dx.doi.org/10.3758/BF03193248

Giesbrecht, T., \& Merckelbach, H. (2006a). Dreaming to reduce fantasy?-Fantasy proneness, dissociation, and subjective sleep experiences. Personality and Individual Differences, 41, 697-706. http://dx.doi.org/10.1016/j.paid.2006.02.015

Giesbrecht, T., \& Merckelbach, H. (2006b). [Dissociative symptoms and sleep]. Tijdschrift voor Psychiatrie, 48, 207-215.

Gregory, A. M., \& Eley, T. C. (2005). Sleep problems, anxiety and cognitive style in school-aged children. Infant and Child Development, 14, 435-444. http://dx.doi.org/10.1002/icd.409

Güleç, M. Y., Altintas, , M., İnanç, L., Bezgin, Ç. H., Koca, E. K., \& Güleç, H. (2013). Effects of childhood trauma on somatization in major depressive disorder: The role of alexithymia. Journal of Affective Disorders, 146, 137-141. http://dx.doi.org/10.1016/j.jad.2012.06.033

Hartmann, E., Zborowski, M., Rosen, R., \& Grace, N. (2001). Contextualizing images in dreams: More intense after abuse and trauma. Dreaming, 11, 115-126. http://dx.doi.org/10.1023/A:1016688110279

Helminen, E., \& Punamäki, R.-L. (2008). Contextualized emotional images in children's dreams: Psychological adjustment in conditions of military trauma. International Journal of Behavioral Development, 32, 177-187. http://dx.doi.org/10.1177/0165025408089267

Kaehler, L. A., \& Freyd, J. J. (2012). Betrayal trauma and borderline personality characteristics: Gender differences. Psychological Trauma: Theory, Research, Practice, and Policy, 4, 379-385. http://dx.doi.org/10.1037/a0024928

Kamphuis, J. H., Tuin, N., Timmermans, M., \& Punamäki, R.-L. (2008). Extending the Rorschach trauma content index and aggression indexes to dream narratives of children exposed to enduring violence: An exploratory study. Journal of Personality Assessment, 90, 578-584. http://dx.doi.org/10.1080/00223890802388558

Ko, Y. H. (1998). Ko's Mental Health Questionnaire (KMHQ). Taipei, Taiwan: Chinese Behavioral Science Corporation.

Kramer, M. (1993). The selective mood regulatory function of dreaming: An update and revision. SUNY series in dream studies. In A. Moffitt, M. Kramer, \& R. Hoffmann (Eds.), The functions of dreaming (pp. 139-195). Albany, NY: SUNY Press.

Kramer, M., \& Brik, I. (2002). Affective processing by dreams across the night. Sleep, 25, 180-181.

Kroth, J., Jensen, L., \& Haraldsson, M. (1997). Correlations of splitting and phobic anxiety with dreaming. Perceptual and Motor Skills, 85, 333-334. http://dx.doi.org/10.2466/pms.1997.85.1.333

Kuwert, P., Braehler, E., Freyberger, H. J., \& Glaesmer, H. (2012). More than 60 years later: The mediating role of trauma and posttraumatic stress disorder for the association of forced displacement in world war II with somatization in old age. Journal of Nervous and Mental Disease, 200, 911-914. http://dx.doi.org/10.1097/NMD.0b013e31826ba129

Mancuso, A., De Vivo, A., Fanara, G., Settineri, S., Giacobbe, A., \& Pizzo, A. (2008). Emotional state and dreams in pregnant women. Psychiatry Research, 160, 380-386. http://dx.doi.org/ 10.1016/j.psychres.2007.06.005 
Miró, E., \& Martínez, M. P. (2005). Affective and personality characteristics in function of nightmare prevalence, nightmare distress, and interference due to nightmares. Dreaming, 15, 89-105. http://dx.doi.org/10.1037/1053-0797.15.2.89

Najam, N., Mansoor, A., Kanwal, R. H., \& Naz, S. (2006). Dream content: Reflections of the emotional and psychological states of earthquake survivors. Dreaming, 16, 237-245. http://dx.doi.org/ 10.1037/1053-0797.16.4.237

Nejad, A. G., Sanatinia, R. Z., \& Yousofi, K. (2004). Dream contents in patients with major depressive disorder. The Canadian Journal of Psychiatry/La Revue canadienne de psychiatrie, 49, 864-865.

Nijenhuis, E. R. S., Van der Hart, O., \& Kruger, K. (2002). The Psychometric characteristics of the traumatic experiences checklist (TEC): First findings among psychiatric outpatients. Clinical Psychology \& Psychotherapy, 9, 200-210. http://dx.doi.org/10.1002/cpp.332

Phelps, A. J., Forbes, D., Hopwood, M., \& Creamer, M. (2011). Trauma-related dreams of Australian veterans with PTSD: Content, affect and phenomenology. Australian and New Zealand Journal of Psychiatry, 45, 853-860. http://dx.doi.org/10.3109/00048674.2011.599314

Pietrzak, R. H., Goldstein, R. B., Southwick, S. M., \& Grant, B. F. (2011a). Prevalence and Axis I comorbidity of full and partial posttraumatic stress disorder in the United States: Results from Wave 2 of the National Epidemiologic Survey on Alcohol and Related Conditions. Journal of Anxiety Disorders, 25, 456-465. http://dx.doi.org/10.1016/j.janxdis.2010.11.010

Pietrzak, R. H., Goldstein, R. B., Southwick, S. M., \& Grant, B. F. (2011b). Personality disorders associated with full and partial posttraumatic stress disorder in the U.S. population: Results from Wave 2 of the National Epidemiologic Survey on Alcohol and Related Conditions. Journal of Psychiatric Research, 45, 678-686. http://dx.doi.org/10.1016/j.jpsychires.2010.09.013

Pietrzak, R. H., Goldstein, R. B., Southwick, S. M., \& Grant, B. F. (2012). Psychiatric comorbidity of full and partial posttraumatic stress disorder among older adults in the United States: Results from wave 2 of the National Epidemiologic Survey on Alcohol and Related Conditions. The American Journal of Geriatric Psychiatry, 20, 380-390. http://dx.doi.org/10.1097/JGP.0b013e31820d92e7

Propper, R. E., Stickgold, R., Keeley, R., \& Christman, S. D. (2007). Is television traumatic? Dreams, stress, and media exposure in the aftermath of September 11, 2001. Psychological Science, 18, 334-340. http://dx.doi.org/10.1111/j.1467-9280.2007.01900.x

Punamäki, R.-L. (1997). Determinants and mental health effects of dream recall among children living in traumatic conditions. Dreaming, 7, 235-263. http://dx.doi.org/10.1037/h0094481

Punamäki, R.-L. (1998). The role of dreams in protecting psychological well-being in traumatic conditions. International Journal of Behavioral Development, 22, 559-588. http://dx.doi.org/ $10.1080 / 016502598384270$

Read, J., \& Ross, C. A. (2003). Psychological trauma and psychosis: Another reason why people diagnosed schizophrenic must be offered psychological therapies. The Journal of the American Academy of Psychoanalysis and Dynamic Psychiatry, 31, 247-268. http://dx.doi.org/ 10.1521/jaap.31.1.247.21938

Read, J., van Os, J., Morrison, A. P., \& Ross, C. A. (2005). Childhood trauma, psychosis and schizophrenia: A literature review with theoretical and clinical implications. Acta Psychiatrica Scandinavica, 112, 330-350. http://dx.doi.org/10.1111/j.1600-0447.2005.00634.x

Ross, C. A. (2000). The trauma model: A solution to the problem of comorbidity in psychiatry. Richardson, TX: Manitou Communications, Inc.

Ross, C. A., Keyes, B. B., Yan, H., Wang, Z., Zou, Z., Xu, Y., . . Xiao, Z. (2008). A cross-cultural test of the trauma model of dissociation. Journal of Trauma \& Dissociation, 9, 35-49. http://dx.doi.org/10.1080/15299730802073635

Ross, C. A., \& Ness, L. (2010). Symptom patterns in dissociative identity disorder patients and the general population. Journal of Trauma \& Dissociation, 11, 458-468. http://dx.doi.org/10.1080/ 15299732.2010 .495939

Schredl, M., \& Engelhardt, H. (2001). Dreaming and psychopathology: Dream recall and dream content of psychiatric inpatients. Sleep and Hypnosis, 3, 44-54.

Schredl, M., Paul, F., Reinhard, I., Ebner-Priemer, U. W., Schmahl, C., \& Bohus, M. (2012). Sleep and dreaming in patients with borderline personality disorder: A polysomnographic study. Psychiatry Research, 200, 430-436. http://dx.doi.org/10.1016/j.psychres.2012.04.036

Semiz, U. B., Basoglu, C., Ebrinc, S., \& Cetin, M. (2008). Nightmare disorder, dream anxiety, and subjective sleep quality in patients with borderline personality disorder. Psychiatry and Clinical Neurosciences, 62, 48-55. http://dx.doi.org/10.1111/j.1440-1819.2007.01789.x

Stompe, T., Ritter, K., Ortwein-Swoboda, G., Schmid-Siegel, B., Zitterl, W., Strobl, R., \& Schanda, H. (2003). Anxiety and hostility in the manifest dreams of schizophrenic patients. Journal of Nervous and Mental Disease, 191, 806-812. http://dx.doi.org/10.1097/01.nmd.0000100924.73596.b8

Stover, C. S., Hahn, H., Im, J. J. Y., \& Berkowitz, S. (2010). Agreement of parent and child reports of trauma exposure and symptoms in the early aftermath of a traumatic event. Psychological Trauma: Theory, Research, Practice, and Policy, 2, 159-168. http://dx.doi.org/10.1037/a0019156 
Suszek, H., \& Kopera, M. (2005). Altered states of consciousness, dissociation, and dream recall. Perceptual and Motor Skills, 100, 176-178. http://dx.doi.org/10.2466/pms.100.1.176-178

Valli, K., Revonsuo, A., Pälkäs, O., \& Punamäki, R.-L. (2006). The effect of trauma on dream content-A field study of Palestinian children. Dreaming, 16, 63-87. http://dx.doi.org/10.1037/10530797.16.2.63

van Dijke, A., Ford, J. D., van Son, M., Frank, L., \& van der Hart, O. (2013). Association of childhood-trauma-by-primary caregiver and affect dysregulation with borderline personality disorder symptoms in adulthood. Psychological Trauma: Theory, Research, Practice, and Policy, 5, 217-224. http://dx.doi.org/10.1037/a0027256

van Winkel, R., van Nierop, M., Myin-Germeys, I., \& van Os, J. (2013). Childhood trauma as a cause of psychosis: Linking genes, psychology, and biology. The Canadian Journal of Psychiatry/La Revue canadienne de psychiatrie, 58, 44-51.

Waldinger, R. J., Schulz, M. S., Barsky, A. J., \& Ahern, D. K. (2006). Mapping the road from childhood trauma to adult somatization: The role of attachment. Psychosomatic Medicine, 68, 129-135. http://dx.doi.org/10.1097/01.psy.0000195834.37094.a4

World Health Organization. (2007). International statistical classification of diseases and related health problems (10th ed., rev.). Retrieved from http://apps.who.int/classifications/icd10/browse/2010/en

Xiao, Z., Yan, H., Wang, Z., Zou, Z., Xu, Y., Chen, J., . . Keyes, B. B. (2006). Trauma and dissociation in China. The American Journal of Psychiatry, 163, 1388-1391. http://dx.doi.org/10.1176/ appi.ajp.163.8.1388

Yu, C. K.-C. (2001). Neuroanatomical correlates of dreaming, II: The ventromesial frontal region controversy (dream instigation). Neuro-Psychoanalysis, 3, 193-201. http://dx.doi.org/10.1080/ 15294145.2001 .10773355

Yu, C. K.-C. (2003). Neuroanatomical correlates of dreaming, III: The frontal-lobe controversy (dream censorship). Neuro-Psychoanalysis, 5, 159-169. http://dx.doi.org/10.1080/15294145.2003.10773422

Yu, C. K.-C. (2007). Emotions before, during, and after dreaming sleep. Dreaming, 17, $73-86$. http://dx.doi.org/10.1037/1053-0797.17.2.73

Yu, C. K.-C. (2008a). Typical dreams experienced by Chinese people. Dreaming, 18, 1-10. http://dx.doi.org/10.1037/1053-0797.18.1.1

Yu, C. K.-C. (2008b). Dream Intensity Inventory and Chinese people's dream experience frequencies. Dreaming, 18, 94-111. http://dx.doi.org/10.1037/1053-0797.18.2.94

Yu, C. K.-C. (2009a). Delusions and the factor structure of typical dreams. Dreaming, 19, 42-54. http://dx.doi.org/10.1037/a0014789

Yu, C. K.-C. (2009b). Confirming the factor structure of the Dream Intensity Inventory. Dreaming, 19, 97-107. http://dx.doi.org/10.1037/a0016296

Yu, C. K.-C. (2009c). Paranoia in dreams and the classification of typical dreams. Dreaming, 19, 255-272. http://dx.doi.org/10.1037/a0017583

Yu, C. K.-C. (2010a). Dream Intensity Scale: Factors in the phenomenological analysis of dreams. Dreaming, 20, 107-129. http://dx.doi.org/10.1037/a0019240

$\mathrm{Yu}$, C. K.-C. (2010b). Dream intensity profile as an indicator of the hysterical tendencies to dissociation and conversion. Dreaming, 20, 184-198. http://dx.doi.org/10.1037/a0020421

$\mathrm{Yu}$, C. K.-C. (2010c). Recurrence of typical dreams and the instinctual and delusional predispositions of dreams. Dreaming, 20, 254-279. http://dx.doi.org/10.1037/a0020879

Yu, C. K.-C. (2011a). The constancy of typical dreams. Asia Pacific Journal of Counselling and Psychotherapy, 2, 51-70. http://dx.doi.org/10.1080/21507686.2010.519037

Yu, C. K.-C. (2011b). The mechanisms of defense and dreaming. Dreaming, 21, 51-69. http://dx.doi.org/10.1037/a0022867

Yu, C. K.-C. (2011c). Pain in the mind: Neuroticism, defense mechanisms, and dreaming as indicators of hysterical conversion and dissociation. Dreaming, 21, 105-123. http://dx.doi.org/10.1037/a0023057

Yu, C. K.-C. (2012a). Dream Motif Scale. Dreaming, 22, 18-52. http://dx.doi.org/10.1037/a0026171

Yu, C. K.-C. (2012b). Testing the factorial structure of the Dream Intensity Scale. Dreaming, 22, 284-309. http://dx.doi.org/10.1037/a0026475

Yu, C. K.-C. (2013a). Obsessive-compulsive distress and its dynamic associations with schizotypy, borderline personality, and dreaming. Dreaming, 23, 46-63. http://dx.doi.org/10.1037/a0030791

$\mathrm{Yu}$, C. K.-C. (2013b). The structural relations between the superego, instinctual affect, and dreams. Dreaming, 23, 145-155. http://dx.doi.org/10.1037/a0032606

Yu, C. K.-C. (2013c). Superego and the repression of affective and dream experiences. Dreaming, 23, 266-276. http://dx.doi.org/10.1037/a0034019 